\title{
Evaluation on Innovation approaches on Performance from Malaysian perspective: A study on Malaysian Building energy saving
}

\author{
M. H. Amlus ${ }^{1,}$, Amlus Ibrahim ${ }^{2}$, Ahmad Zaidi Abdullah ${ }^{1}$, Nurhafiza Azizan ${ }^{1}$ and Ummi Naeimah Saraeh ${ }^{1}$, \\ ${ }^{1}$ Universiti Malaysia Perlis, Malaysia \\ ${ }^{2}$ Universiti Utara Malaysia, Malaysia
}

\begin{abstract}
Lately Malaysia energy consumption versus generation rapidly shows increasing due to increasing of load. This phenomenon happened following to advanced country development. Lacking on design and without energy management approach the energy consumption and monthly electrical bill will steadily increased and support the increasing of world carbon emission. Therefore the aim of this work is to approach the simplest innovation task-energy audit, which is load-apportioning strategy. This approach using matching the usage of equipment with fully utilized space and reschedules the time of usage. A one week data was collected by logged power meter at main switchboard at selected building using Fluke Power Recorder. From the data collected, current usage of every load can be determine, then load will be arrange into a group with same portion and same time of usage. The result shows clearly the energy consumption for every single day and indicates the highest and lowest peak. From this work the apportioning strategy implemented by rearrange the load following type of room application. After the arrangement, new measurement was taken and a very good result was established. This work also can be further apply for a huge load that can be save a lot of money for owner especially government by energy saving.
\end{abstract}

\section{Introduction}

The global electrical energy demands have been on constant rise due to its many desirable factors that makes its use suitable for both domestic and general production use in realizing a wide range of products and services. Load apportioning strategy is a way of matching the with the equipment or individual use of energy.

Normally use to determine the payment scale, which an individual meet during each billing payment made. Unfortunately, many of these payments have not been matching with individual's use, an attribute of installations that are not efficient and individual preference based. To counter this, considerations need to be made on each consumption scenario with key interest focusing on individual's electricity demand and consequent billing method.

One of the best strategies to cut down the wasteful use of electric energy is the implementation of load apportioning. This refers to considering all cost factors that come with energy distribution and equally distributing the total cost among its users. Load apportioning brings forth responsible power use as it embarks on the concept of" pay as you use". There exist several apportionment policies each with their unique characteristic that suit different scenarios well distributors [1]. Building that are designed to host various entities like business or for accommodating people use the policy that best suits them and the consumers they host. At an instance, apportioning policy may best suit an individual who uses power throughout the day while at another instance another policy fits best a consumer who only uses power a fraction of a day [2].

\section{Method}

Figure 1 presented how the project was done, which is use a main equipment such as fluke 434 Series II power quality to measure the power and energy in the blocks assigned for this project. This equipment is one of the best equipment in measuring the power and energy, as energy saving equipment becomes more and more common in facilities the need to explore where energy is being wasted has become more and more important.

Figure 2 show the connection of Gluke 434 at site during logged data. At the same time these important pieces of energy saving equipment like motor drives and electronic lighting have the potential to disrupt the electrical system due to power quality problems. The Fluke 434 Series II Power Quality can monetize the cost of energy waste due to poor power quality and is ideal for characterizing power quality, conducting load studies and capturing hard-to-find voltage events over a user-defined period of time. 
The Fluke 434 II Energy Analyzer is the ideal tool for advanced energy logging and energy monetization, identifying the most energy-wasteful areas of your facility. After finding the main aim which is the highest building that consume the energy, the focus will be on that building to analyze the problem in order to come out with the best solutions for the problem to be solved. Apportion the load between all of the equipments to get the result of which of the equipment consume the highest energy in order to control that equipment in term of use to be able reduce the unnecessary use during and after the working hours which causes the waste of energy. In addition, giving suggestions that may help to be a better solution in the future.

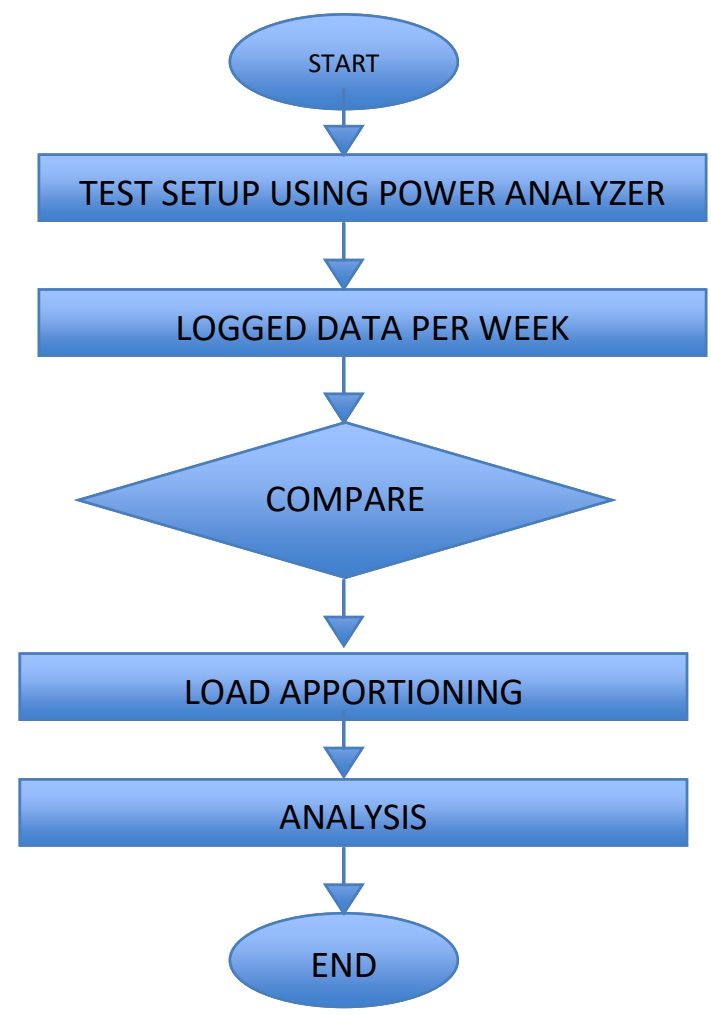

Figure 1:Project Methodology

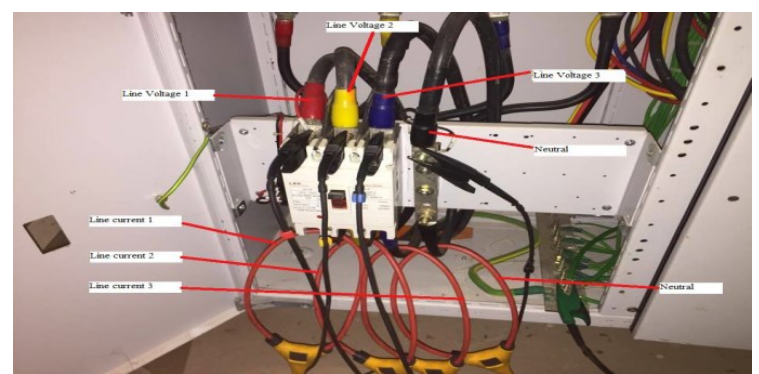

Figure 2:Fluke 434 connection for measurement

correction

to solve the problem, as one way to do so is to add a capacitive bank to improve the power factor.

As the low power factor, can cause large kVA rating of equipment of electrical machinery such as switch gear,
The formula used for power and energy;

$P=\sqrt{3} \times \mathrm{I} \times \mathrm{V} \times \cos \emptyset \ldots(\mathrm{kW})$

$\mathrm{E}=\mathrm{P} \times \mathrm{t}(\mathrm{kWh})$

\section{Result Analysis}

Figure 3 shows the total maximum consumption of energy in a week. Energy follows the power in terms of consumption as it is shown similarly. The consumption of energy is almost same with the power during the working day and office hours $(8 \mathrm{am}-5 \mathrm{pm})$ in a day as there is running of classes, labs and other equipment such as air condition and lamps. In all the time duration shown the

Figure 1 below, the peak of consumption usually occurs from 8am to $5: 00 \mathrm{pm}$ as the noon time with a $33^{\circ} \mathrm{C}$. which needs to use air conditions which leads to consume more energy as the air conditions consider as inductive load while the lamps, laptops and water heaters as the inductive load consume more energy than resistive load.

On the other hand, the lamps don't consume more energy but still need to be controlled to avoid the waste of any amount of energy. At night, energy still being consumed, as the lights not switched off to manage the waste of energy, there will be no cost for electrical energy management once the lights switched off at the night time.

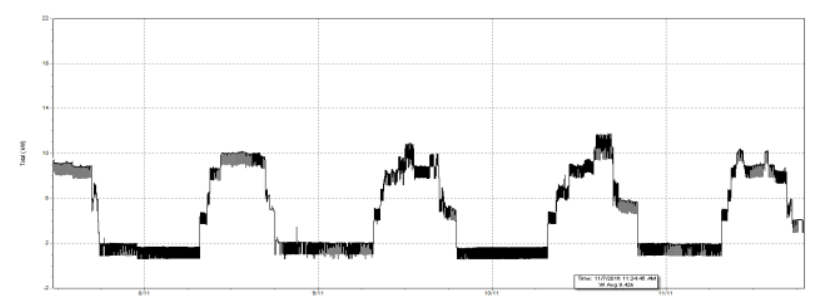

Figure 3:Average consumption in a week

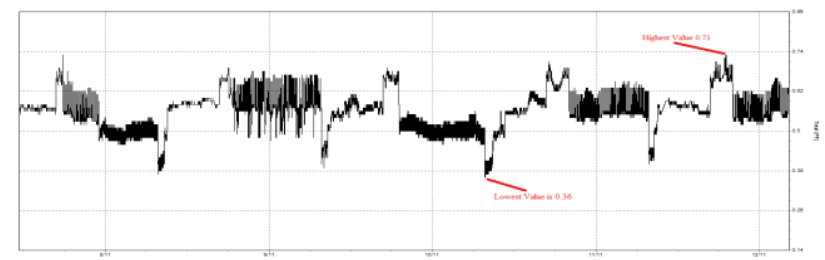

Figure 4: Power Factor measurement in a week.

Figure 4 shows the power factor in a week period as the highest value of power factor reached to be 0.73 only while the lowest value of power factor index was 0.36 . It can be clearly seen that the power factor in not satisfied as it is not even approach to the value of 0.85 , which is the standard for power factor, by TNB. It means that the load has a problem and needs power factor

transformers and alternators, as kVA rating is inversely proportional to power factor, the smaller the power factor, the larger is the kVA rating. Thus, at low power factor, making the equipment expensive and lager as the $\mathrm{kVA}$ rating has to be made more. 
Furthermore, the large current conducted at low power factor, which causes larger copper losses in all the elements of the supply system. This results in very poor efficiency. From the diurnal electricity consumption patterns, fluctuations in the graphs are noticed in the hourly consumption. The consumption patterns of energy show several peaks and troughs throughout the day. Electrical energy consumption is different from one of weekday to another while closely same in weekends. It can be seen from the graph in Figure 3 that on Monday the energy consumption was approximately to be $74.02 \mathrm{kWh}$ with a temperature of $30^{\circ} \mathrm{C}$ as the start of the week and meant to be all the staff are there

On Tuesday, the consumption turned to be $79.3 \mathrm{kWh}$ which is higher than Monday as there was an increase in the temperature with to be $33^{\circ} \mathrm{C}$. On Wednesday, the consumption was $73.66 \mathrm{kWh}$ in a temperature of $33^{\circ} \mathrm{C}$, on Thursday the consumption increased a bit to be 75.73 $\mathrm{kWh}$ under a temperature of $33^{\circ} \mathrm{C}$, on Friday consumption was $74.71 \mathrm{kWh}$ under the same degree of temperature while Saturday and Sunday with consumption of 14.09 $\mathrm{kWh}$ and $15.18 \mathrm{kWh}$ respectively under temperature of $33^{\circ} \mathrm{C}$.

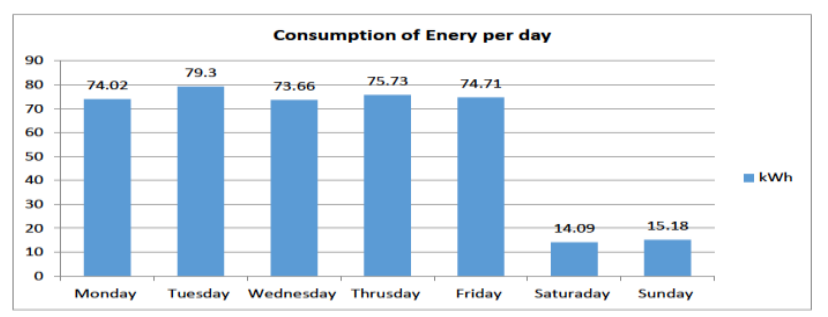

Figure 5: Percentage of Energy consumption per day

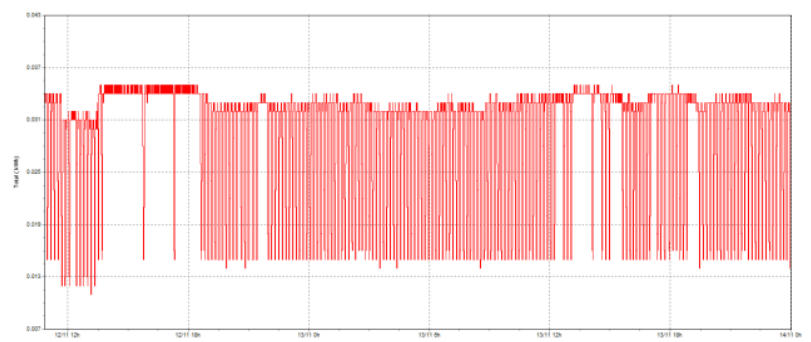

Figure 6: Percentage of Energy consumption per day

While during weekends, the total consumption of energy at least less than half the maximum total consumption on a weekday. In weekends activities are not carried out and only some staffs are working such as staffs in the security office as well as some lecturers and other staffs who return to the campus for a short duration to do some works.

As classes are not conducted on weekends and thus contribute to a significant reduction in energy consumption of both days This observation further proves that lecturer activities contribute to a major role in electricity consumption of block 6 first floor as the lecturers will be there as shown in Figure 6 .

During weekends, still there is an amount of energy to be used or wasted, thus, appliances and equipments should only be operated when needed, otherwise those appliances and equipments need to be turned off to save the energy. 14.09 $\mathrm{kWh}$ on Saturday and $15.18 \mathrm{kWh}$ on Sunday should be saved at least when there is no formal activities the other appliances should be switched off.

\section{Conclusion}

By referring to the findings, some of the strategies can be suggested in utilizing electricity wisely and effectively. Firstly, it is important to start with changing consumers' behavior and habit in utilizing appliances and equipments wisely and effectively.

Thus, those appliances and equipments should only be operated when needed, otherwise those appliances and equipments need to be turned off. Secondly, consider high efficient appliances and equipments.

Therefore, by taking those important parameters in consideration, behavior and technology, electricity consumption could be managed wisely and effectively. Thus, it needs strong systematic and holistic approaches to be guided by government to consumers.

\section{References}

Miller, J.R \& Simon, P (2008). Electrochemical capacitor for energy management.Science Magazine, 321(5889), 651-652.

Petersen, J.E, Shunturov, V., Janda, K., Platt, G., \& Weinberger, K.(2007).Dormitory residents reduce electricity consumption when exposed to real-time visual feedback and incentives. International Journal of Sustainability in Higher Education, , 8(1), 16-33.

Das, D., Kothari, D.P., \& Kalam, A.(1995) . Simple and efficient method for load flow solution of radial distribution networks. International Journal of Electrical Power \& Energy System, 17(5), 335-346

B.,\&Kang,S. (2001).A Study on Automatic control System for Real Time Optimized Load Apportionment Between Power Generating Sets. Power Equipment, 6, 26-30

Abrahamse,W., Steg, L.,Vlek,C.\& Rothengatter, T. (2005).A review of intervention studies aimed at household energy conservation. Journal of environmental psychology,

25(3),273-291 